\title{
FUNCTIONAL OUTCOME ANALYSIS OF MANAGEMENT OF COMPOUND FRACTURES OF TIBIA WITH ILIZAROV FIXATOR
}

\author{
Kumaresapathy Shanmugam 1 , Kalyanasundaram Kolundan², Srinivasan Anbu ${ }^{3}$
}

${ }^{1}$ Assistant Professor, Department of Orthopaedics, KAP Viswanatham Government Medical College, Tiruchirapalli. ${ }^{2}$ Associate Professor, Department of Orthopaedics, KAP Viswanatham Government Medical College, Tiruchirapalli. ${ }^{3}$ Associate Professor, Department of Orthopaedics, KAP Viswanatham Government Medical College, Tiruchirapalli.

\section{ABSTRACT}

\section{BACKGROUND}

Tibia is the most frequent site of an open fracture, with incidence ranging from $49.4 \%$ to $63.2 \%$. Their treatment, prognosis, and outcome are mainly determined by the mechanism of injury, degree of comminution, soft tissue injury and displacement. The best mode of treatment is elusive in high-energy tibial fractures. Ilizarov fixator was chosen to fix those fractures that produced high rate of complications with most conventional methods of fixation.

\section{MATERIALS AND METHODS}

This study consists of 40 cases of grossly comminuted compound fracture of tibia treated using Ilizarov technique at Govt. Royapettah Hospital, Chennai from 2004 to 2008.

\section{RESULTS}

In our study, all 40 cases were followed up until union. Patients were assessed for pain and functional limitations, examined for angular and rotational malalignment and range of motion. Pin tract infection occurred in $4(10 \%)$ cases. 2 (5\%) patients had an angulation of $5^{\circ}$ at the fracture site, and $4(10 \%)$ had shortening between $1-2 \mathrm{~cm}$. Union was clinically verified by the absence of pain and motion while fully weight bearing on the tibia with the frame still attached and destabilised. Union was determined to be the time when fracture healing occurred and all forms of immobilisation or support were discontinued. Union occurred at an average of 5.3 months (3.5 to 8.5 months).

\section{CONCLUSION}

Ilizarov technique has a definite role in the management of fracture of tibia like open comminuted fracture, open segmental fracture and open fracture with bone loss. It reduces hospital stay, allows full functional recovery, permits early weight bearing and gives definite union.

\section{KEYWORDS}

Compound Fracture, Open Fracture, Comminuted Tibia Fracture, Ilizarov Fixation.

HOW TO CITE THIS ARTICLE: Shanmugam K, Kolundan K, Anbu S. Functional outcome analysis of management of compound fractures of tibia with Ilizarov fixator. J. Evolution Med. Dent. Sci. 2017;6(6):470-477, DOI: 10.14260/Jemds/2017/103

\begin{tabular}{|c|c|}
\hline BACKGROUND & $\mathrm{r}$ treatment, \\
\hline $\begin{array}{l}\text { Tibia is the most frequent site of an open } \\
\text { incidence ranging from } 49.4 \% \text { to } 63.2 \% .^{(1,2,3)} \text { In }\end{array}$ & $\begin{array}{l}\text { etermined by the mechanism of injury, degree of } \\
\text { omminution, soft tissue injury and displacement.(10) }\end{array}$ \\
\hline
\end{tabular}

the highest road accident rates in the world.(4) A large proportion of vehicles involved are two wheelers. The lower limbs are involved in $49.6 \%$ of motor cycle accidents.(5)

By its very location the tibia is prone to frequent injuries. Furthermore, the blood supply of the tibia is precarious. High-energy tibial fractures are associated with compartment syndrome or neurovascular injuries.(6) Open fractures have a higher infection rate than closed fractures and the rate increases with increasing severity of soft tissue injury. $(7,8)$

The risk of delayed union and non-union is increased with comminution. ${ }^{(9)}$

Financial or Other, Competing Interest: None.

Submission 08-12-2016, Peer Review 05-01-2017,

Acceptance 11-01-2017, Published 19-01-2017.

Corresponding Author:

Dr. Kumaresapathy Shanmugam,

No. 55, Ahmed Colony $3^{\text {rd }}$ Cross,

Ramalinga Nagar, Woraiyur, Trichy-620003.

E-mail: drkumareshtry@gmail.com

DOI: $10.14260 /$ jemds $/ 2017 / 103$

There are so many Treatment Options Available for Management of Fracture of Tibia-

1. Closed reduction and cast treatment.

2. Pin and plaster technique.

3. External fixator.

4. Intramedullary nailing.

5. Rigid fixation with plate and screws.

Each method has its own merits and demerits. The high incidence and variety of these fractures may at times cause difficulties in choosing the type of treatment. The optimal treatment should include anatomical reduction of segments, stable fixation and early mobilisation and function.

The best mode of treatment is elusive in high-energy tibial fractures. Because of the tenuous soft-tissue coverage of the tibia, plate fixation has typically been associated with an unacceptably high prevalence of wound complications, especially when it has been performed for more severe fractures.(11,12) Tibial nailing though in popular use also has its own share of complications. Malunion occurs after up to $37 \%$ of tibial nailing procedures.(13) Severe comminution 
further adds to the complication. Intramedullary nail insertion is also shown to interfere with circulation in the diaphyseal cortex. ${ }^{(14,15)}$ External fixator only provided a temporary measure with the additional morbidity associated with pin tract infections. Moreover, early weight bearing could not be encouraged.

Ilizarov fixator was chosen to fix those fractures that produced high rate of complications with most conventional methods of fixation. It also provides opportunity for wound care and management of open fractures. The timing of soft tissue coverage is a subject of controversy. The standard teaching has been that open fractures remain open until the patients returned to the operating room for a secondary debridement to ensure that adequate debridement of necrotic tissue from the wound was done prior to wound closure.(16)

Transosseous osteosynthesis of fracture, according to Ilizarov is essentially a non-surgical method except for the insertion of wires which are tensioned and fixed to circular rings in a sterile operative room. The structure is stable and enables the patient to bear weight on the affected limb straight away even in comminuted fractures.

The Advantages of Fixation with Ilizarov Apparatus Compared with others are-
1. Stability.
2. Preservation of blood supply.
3. Maintenance of function.
4. Negligible blood loss.
5. Early weight bearing.

Our study is to highlight the important role of Ilizarov ring fixator for grossly comminuted compound fracture of tibia. It helps to achieve stable fixation of the limb at multiple levels and permits healing of fracture. Since it is a multidirectional, multiplanar, multilevel fixator system, it allows cyclic axial micromotion at fracture site and favours fracture union, enables the surgeon to correct malalignment and in case of bone loss, to perform adequate limb lengthening.(17)

\section{Aim of Study}

Aim of our study is to analyse the result of 40 cases of grossly comminuted compound tibial fracture treated with Ilizarov technique.

\section{Mechanism of Injury}

Direct trauma like road traffic accidents often cause concomitant severe soft tissue damage with a high incidence of open fractures.(3) The lack of soft tissue covering of the tibial shaft and difficult blood supply make these fractures vulnerable to infection and non-union. The exposed subcutaneous border of tibia offers little protection from a direct blow in motor vehicle vs. pedestrian accidents, and high energy trauma involve the tibia in over $15 \%$ of accidents.

Damage of extremity, associated with significant soft tissue injury is a result of high energy impact between an object and the limb. The amount of energy dissipated during this collision is determined by the following equation: $\mathrm{EK}=\mathrm{mv}^{2} / 2$; EK is kinetic energy, $\mathrm{m}$ the mass and $\mathrm{v}$ the speed.

\section{MATERIALS AND METHODS}

This study consists of 40 cases of grossly comminuted compound fracture of tibia treated using Ilizarov technique at Govt. Royapettah Hospital, Chennai from 2004 to 2008.

\section{The following Types of Cases were Included-}

1. Compound diaphyseal fracture comminuted.

2. Compound periarticular fracture.

3. Compound tibial plateau fracture.

4. Compound metaphyseal fracture with shaft extension.

5. Compound segmental fracture.

6. Compound diaphyseal fracture with bone loss.

\begin{tabular}{|c|c|c|}
\hline Age Group & No. of Cases & Percentage \\
\hline $10-20$ & 2 & $5 \%$ \\
\hline $20-30$ & 16 & $40 \%$ \\
\hline $30-40$ & 16 & $40 \%$ \\
\hline $40-50$ & 4 & $10 \%$ \\
\hline $50-60$ & 2 & $5 \%$ \\
\hline \multicolumn{3}{|c|}{ Table 1. Age Distribution } \\
\hline
\end{tabular}

All 40 cases were males.

\begin{tabular}{|c|c|c|}
\hline Sex & No. of Cases & Percentage \\
\hline Male & 40 & $100 \%$ \\
\hline \multicolumn{2}{|c|}{ Table 2. Sex Distribution } \\
\hline
\end{tabular}

\begin{tabular}{|c|c|c|}
\hline Mode of Injury & No. of Cases & Percentage \\
\hline RTA & 36 & $90 \%$ \\
\hline $\begin{array}{c}\text { H/O Fall } \\
\text { from Height }\end{array}$ & 4 & $10 \%$ \\
\hline \multicolumn{2}{|c|}{ Table 3. Mode of Injury } \\
\hline
\end{tabular}

\begin{tabular}{|c|c|c|}
\hline Grade & No. of Cases & Percentage \\
\hline Grade-I & 6 & $15 \%$ \\
\hline Grade-II & 6 & $15 \%$ \\
\hline Grade-IIIA & 8 & $20 \%$ \\
\hline Grade-III B & 20 & $50 \%$ \\
\hline \multicolumn{2}{|c|}{ Table 4. We treated Open Fracture } \\
with Gustilo Classification \\
\hline
\end{tabular}

\begin{tabular}{|c|c|c|}
\hline Sl. No. & Side Involved & No. of Patients \\
\hline 1. & Right lower limb & 22 \\
\hline 2. & Left lower limb & 18 \\
\hline \multicolumn{3}{|c|}{ Table 5. Side of Affected Limb } \\
\hline
\end{tabular}

\begin{tabular}{|c|c|c|}
\hline Sl. No. & Associated Injuries & No. of Patients \\
\hline 1. & Distal Radius Fractures & 2 \\
\hline 2. & Fracture Clavicle & 1 \\
\hline 3. & Metatarsal Fracture & 2 \\
\hline \multicolumn{3}{|c|}{ Table 6. Associated Injuries } \\
\hline
\end{tabular}




\section{We used AO Classification.}

\begin{tabular}{|c|c|c|}
\hline $\begin{array}{c}\text { Proximal }(1 / 3) \\
\text { Tibia }\{41\}\end{array}$ & $\begin{array}{c}\text { Middle }(1 / 3) \\
\text { Tibia }\{42\}\end{array}$ & $\begin{array}{c}\text { Distal }(1 / 3) \\
\text { Tibia }\{43\}\end{array}$ \\
\hline 41.A. 3. 3 & 42.B. 3.3 & 43.B. 3. 3 \\
\hline \multirow[t]{15}{*}{ 41.C. 2} & 42.B. 3. 1 & 43.B. 3. 3 \\
\hline & 42.C. 2.1 & \\
\hline & 42.C. 2.1 & \\
\hline & 42.B. 3.3 & \\
\hline & 42.B. 3. 1 & \\
\hline & 42.C. 2.1 & \\
\hline & 42.C. 2.1 & \\
\hline & 42.C. 2.1 & \\
\hline & 42.B. 3.1 & \\
\hline & 42.C. 3.1 & \\
\hline & 42.C. 2.1 & \\
\hline & 42.C. 2.1 & \\
\hline & 42.C. 2.1 & \\
\hline & 42.B. 3.1 & \\
\hline & 42.C. 3.1 & \\
\hline \multicolumn{3}{|c|}{ Table 7. Type of Fracture } \\
\hline
\end{tabular}

\section{Number of Cases}

Proximal (1/3) Tibia- 4

Middle (1/3) Tibia- 32.

Distal (1/3) Tibia- 4.

\section{Pre-Operative Evaluations \\ Examination}

Evaluation of the extent of injury (Eg. Ligament damage, open fracture, etc.).

Range of motion.

\section{X-rays}

X-ray of leg AP/Lateral view including knee to ankle joint taken for all cases.

Length of space between tibial plateau and fracture, Length of fracture, Length of space between fracture and tibial plafond and associated fibular fractures were assessed.

\section{Templating}

Use of opposite normal extremity to help template ring sizes.

Space between inner rings must be greater than the length of fracture comminution. Assess potential for transfibular wires.

\section{Our Basic Operative Technique}

All cases were done under spinal anaesthesia.

\section{Position}

Patients were placed supine in the operating table with sand bag under the thigh and another under the heel leaving the entire operating area free for the surgeon.

\section{Methods}

Frame Construction: Two half rings are selected that are 2-3 $\mathrm{cm}$ larger than the largest diameter of the injured limb. The rings are positioned in the same plane, and a bolt and nut anchor both ends of the half rings. Typically, a four-ring assembly is required with 2 rings proximal and 2 distal to the fracture site. In fractures with small segments, two rings are used on large fragments and ring \& drop post used for smaller fragments. Two proximal \& distal rings are connected via four rods of appropriate length.

\section{Surgical Strategy}

Firstly, preliminary reduction of fracture and insertion of transverse proximal and distal wires is done. Then, the frame is brought to the wires.

Only hand drill was used for wire placement. First wire passed through the head of fibula. It was attached to proper sized ring with wire fixation bolt. Tibial fractures generally require $140,160,180$ rings.

The second ' $K$ " wire was passed through tibia from anterolateral to posteromedial direction.

The distal ring secures two ' $\mathrm{K}$ ' wires; one through fibula and another through tibia. The intermediate loose rings were connected with proximal and distal rings by connecting rods. The proximal, distal rings were tensioned. Fracture was reduced by distraction of rods and reduction checked with Xray or image intensifier. Then intermediate rings were fixed with 2 ' $\mathrm{K}$ ' wires/olive wires according to topographical anatomical atlas. Wires manipulated according to displacement of fragments.

Bayonet tipped $1.8 \mathrm{~mm}$ ' $\mathrm{K}$ ' wire used for all age groups and $1.5 \mathrm{~mm}$ olive wire for translation, displacement correction and for interfragmentary compression. Application of distraction across the fracture site if shortening is present. Tensioning of proximal and distal wires is done. Tensioner was used for tensioning in all cases. This achieves partial reduction in the coronal plane and helps to suspend the leg in the middle of the frames. We used Betadine dressing for each pin tract. After checking the position with X-ray, compression was given at fracture site.

\section{Procedure for Acute Fractures of Tibia}

Type A1 Assembly- Transverse Proximal Fractures

In proximal fractures, two pairs of wires are initially placed, the first pair in the proximal epiphysis, the second pair in the distal epiphysis. The planes formed should be perpendicular to the axis of the fracture segments.

\section{Type A2 Assembly- Oblique Proximal Fracture}

In oblique fractures, it is better to use olive wires in opposite positions.

Type B1 Assembly- Transverse Diaphyseal Fractures It is necessary to use two intermediate rings one placed approximately two centimetres proximal to the fracture site and the other distal to it.

\section{Type B2 Assembly- Oblique Diaphyseal Fractures}

It is best to use wires with stoppers.

1. Interfragmentary compression may be exerted by means of the opposing forces applied between two rings fixed to the bone with wires.

2. By using two wires with stoppers, the stoppers are placed on opposite sides of the bone, on either side of the fracture.

3. By using two wires placed through the fractures site reduction is obtained by applying traction. 
4. Interfragmentary compression may be exerted with a single wire with stopper placed in an oblique position.

\section{Type B3 Assembly}

Only Variation from B2 Assembly consisting of fixation of the third Fragment with stopper wire, two wires with stoppers are placed approximately two centimetres above and below the fracture site and opposing directions. A wire with a stopper is inserted, through the third fragment from posts attached to third ring.

\section{Type C1 Assembly- Transverse Distal Fracture}

Fixation of the distal tibia entails the use of three wires placed on a ring. One of the wires is transtibiofibular. A fourth wire with a stopper may also be used. It is placed approximately two centimetres proximal to the distal ring and fixed to the ring with two support posts or half ring with threaded rods.

\section{Type C2 Assembly- Oblique Meta-Epiphyseal Distal Fracture}

When the distal fragment is small and difficult to stabilise, the assembly must be extended across the ankle joint to the calcaneus.

\section{Correction of Lateral Displacement in Acute Fractures}

Two crossed wires are inserted into the proximal segment.

1. A wire with a support stopper is used for the distal segment.

2. The limb is placed in traction in order to distract the two segments apart.

\section{For Rotational Displacement}

A series of buckles and posts with threaded rods all facing the same direction on the distal ring may be used. Derotation of the fragments can be carried out in controlled mechanical fashion in this way.

\section{Corticotomy}

The term corticotomy was first used by Ilizarov after he conducted many controlled animal experiments in which he tried out this technique. After his experiments, he concluded that preservation of endosteal tissues and vasculature results in more rapid and reliable bone formation and consolidation.

Corticotomy is transaction of only the bone cortex with preservation of the periosteum, endosteum and the bone marrow with its blood supply. This indicates a small portal entry and minimal disruption of surrounding soft tissue and manual osteoclasis of the remainder of the cortical circumference.

\section{Follow-Up}

All corticotomy patients were treated as inpatients during distraction period. X-rays were taken every week to review callus amount and quality and angulations of the transported segment. Once distraction period was completed and if transport segment was satisfactory, patient was discharged and reviewed once in two weeks.

Patients were discharged once pain subsided and patient was ambulated in a walker, with partial weight bearing. On follow-up, the following parameters were reviewed and treated accordingly.

1. Wire breakage.

2. Pin site infection.
3. Joint stiffness.

4. Neurovascular deficit.

5. Pain on walking.

6. Deformity.

\section{DISCUSSION}

In our study, the highest number of patients was in their $2^{\text {nd }}$ to $4^{\text {th }}$ decade $(80 \%)$. RTA was the most common mode of injury $(80 \%)$ followed by fall from height. In our study, there was not a single case with bilateral fractures. 2 patients had associated Ipsilateral Distal Radius Fracture, 1 patient had Ipsilateral Clavicle fracture, and two patients had associated ipsilateral metatarsal fracture. Most of the patients, reported within 36 hours of injury. Majority of the injured patients fell in Gustilo type IIIB (50\%). Type of 42.C. 2.1 of A.O. Classification was the most common type of fracture encountered in our study. The shortest follow up period was 8 months and the longest was 22 months. Early complications were encountered in 4 patients; these were pin tract infections. Late complications encountered were malunion with valgus deformity in 1 patient, procurvatum deformity in 1 patient and shortening in 4 patients. The average stay in hospital was about 20 days. Autogenous iliac crest graft was used in 8 out of 40 patients for delayed cases.

\section{Clinical Illustrations}

Case 1

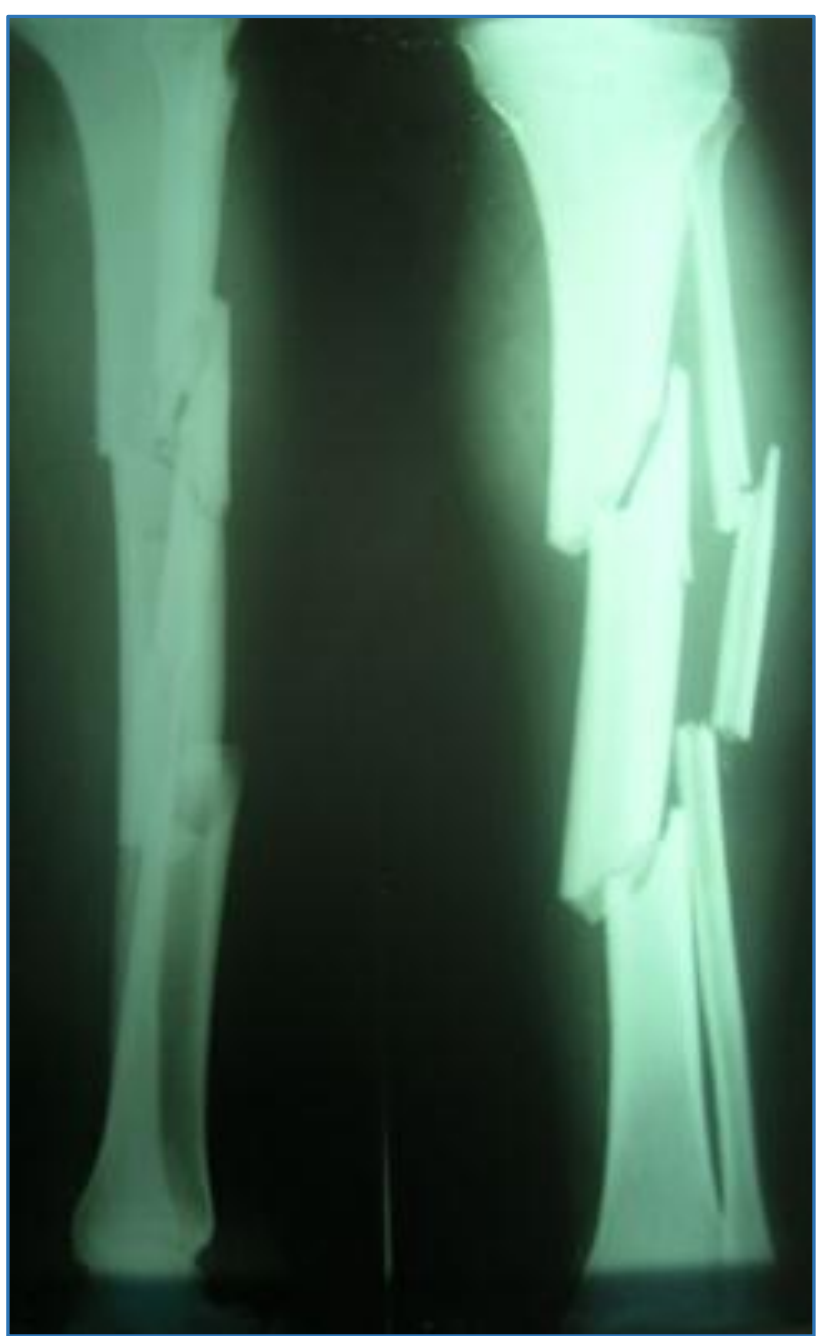

Figure 1. Pre-op X-ray 


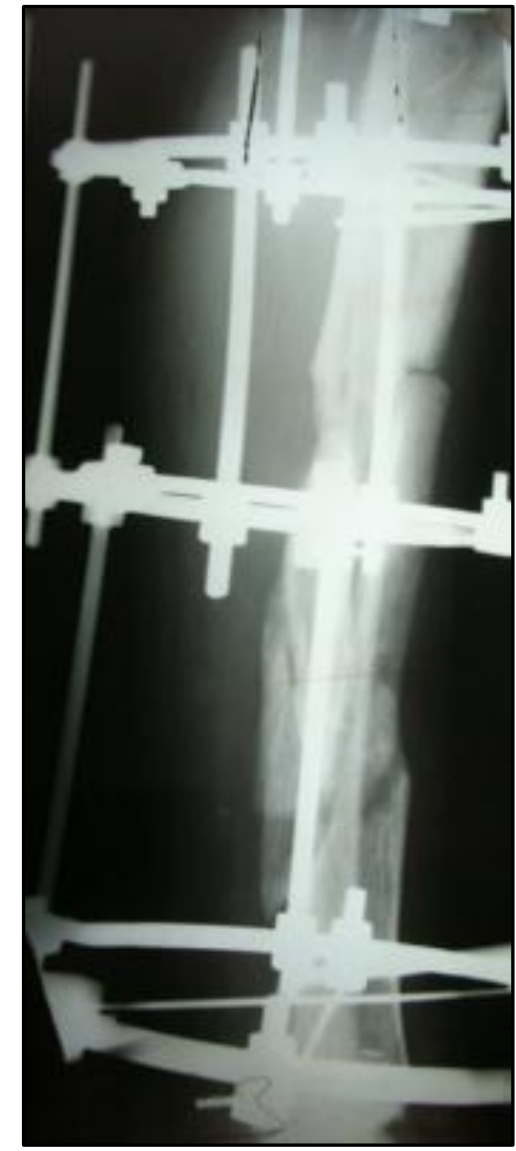

Figure 2. Immediate Post-op

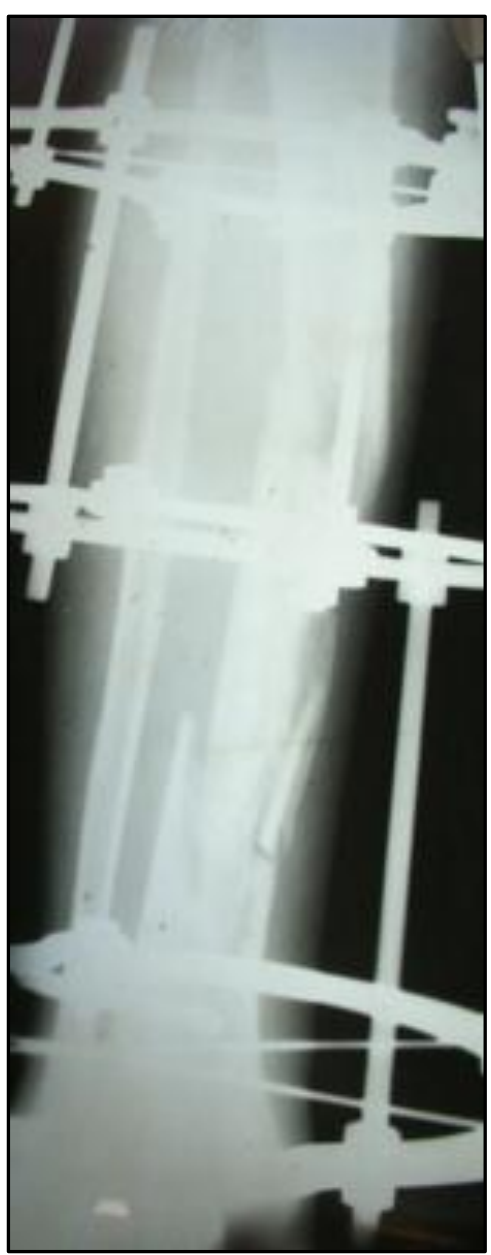

Figure 3. Immediate Post-op

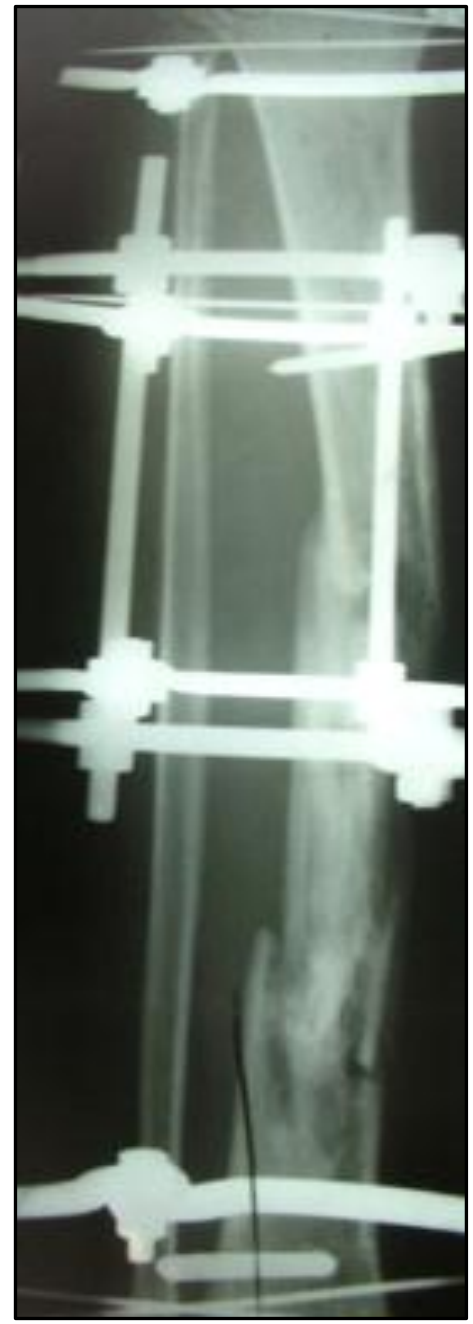

Figure 4. 12 Weeks

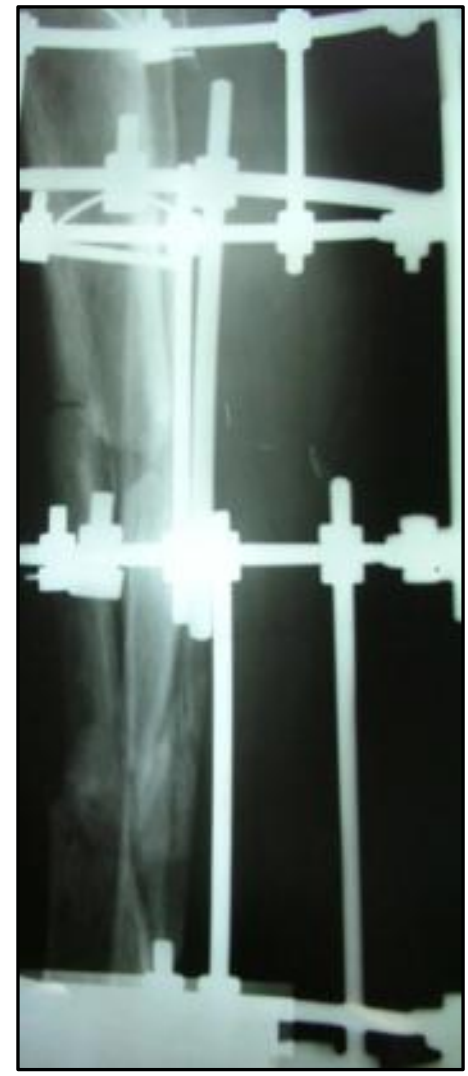

Figure 5. 30 Weeks 


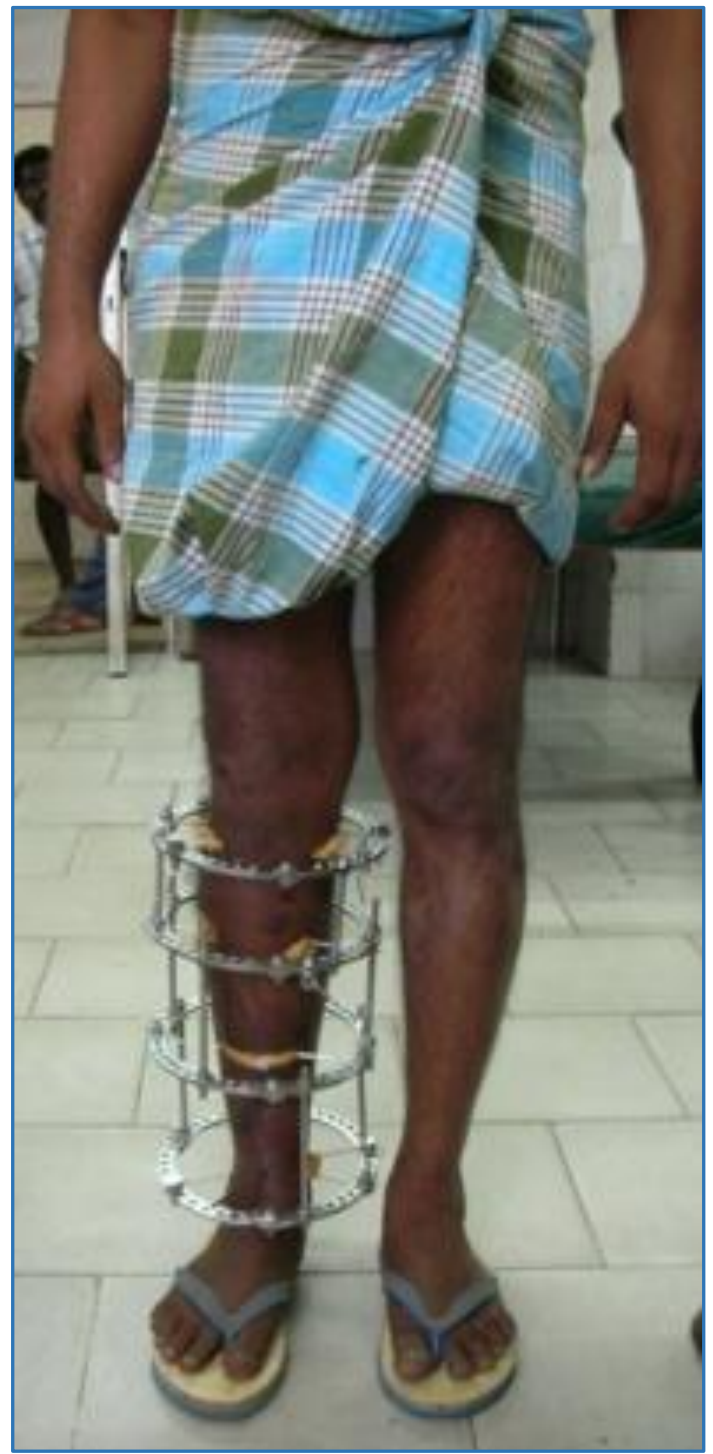

Figure 6. Clinical Picture 30 Weeks

\section{Case 2}

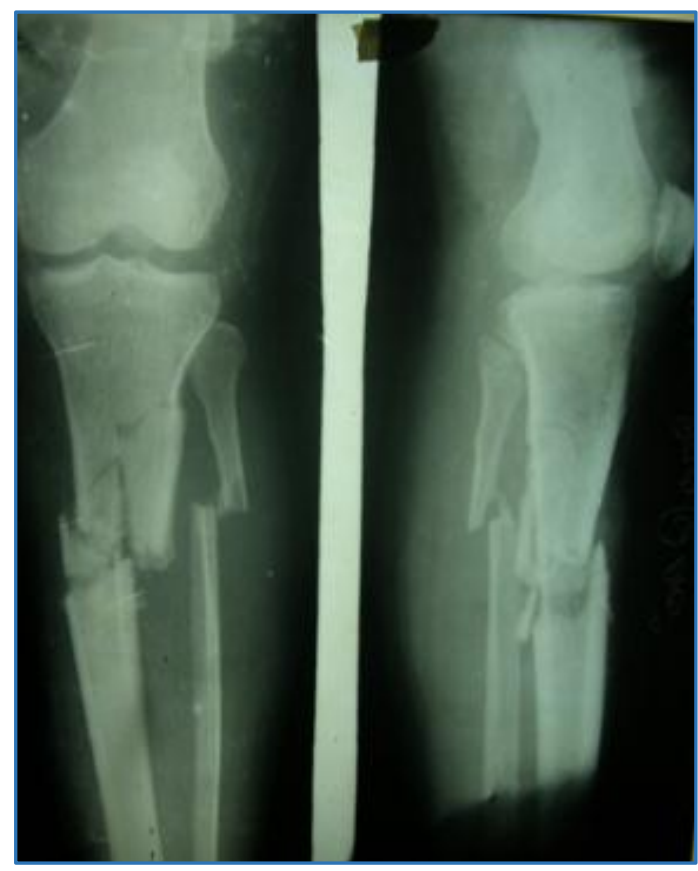

Figure 7. Pre-op

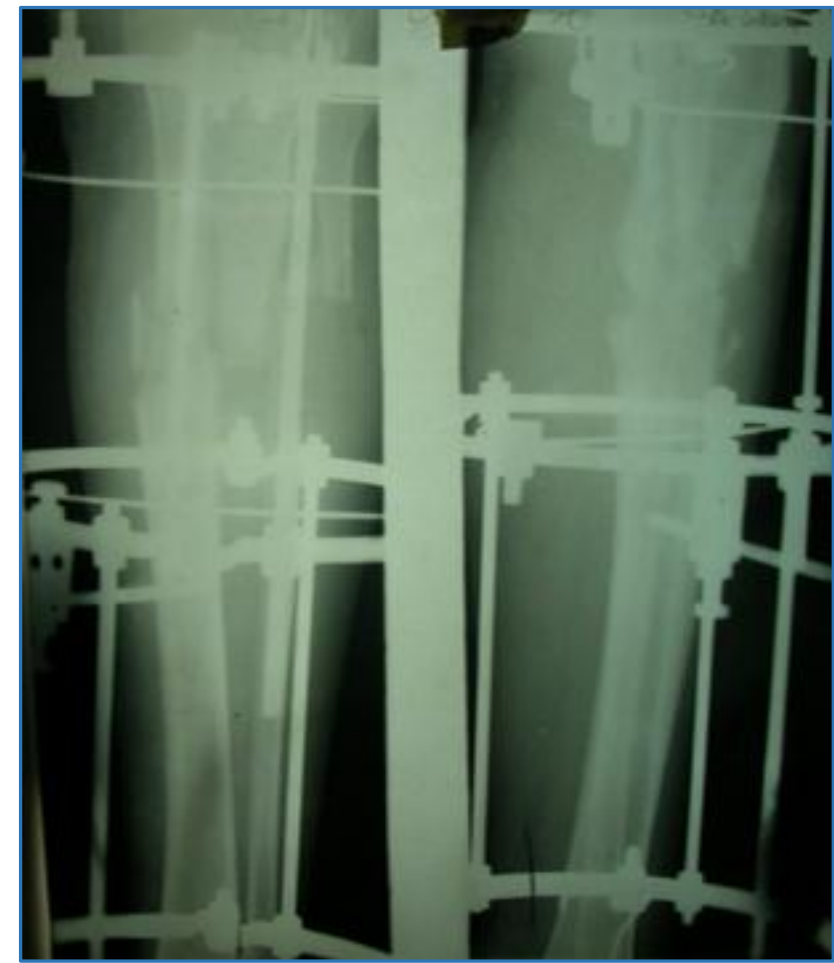

Figure 8. Immediate Post-op

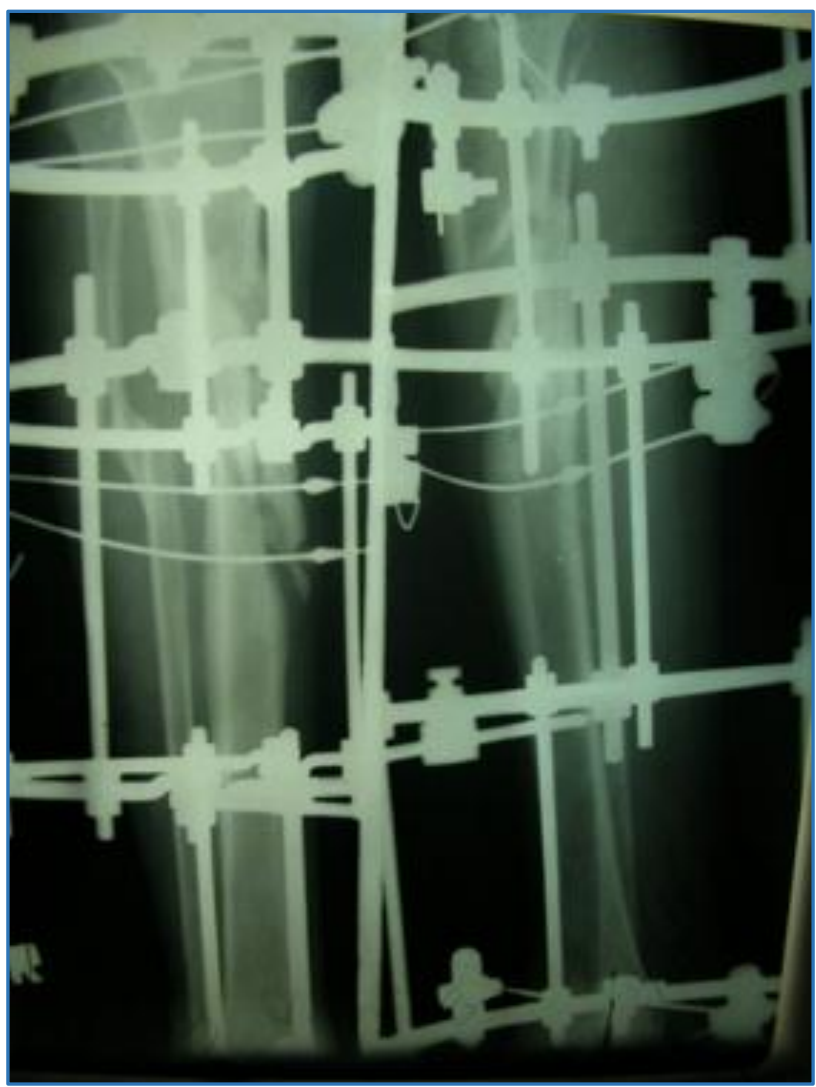

Figure 9. 30 Weeks Post-op 


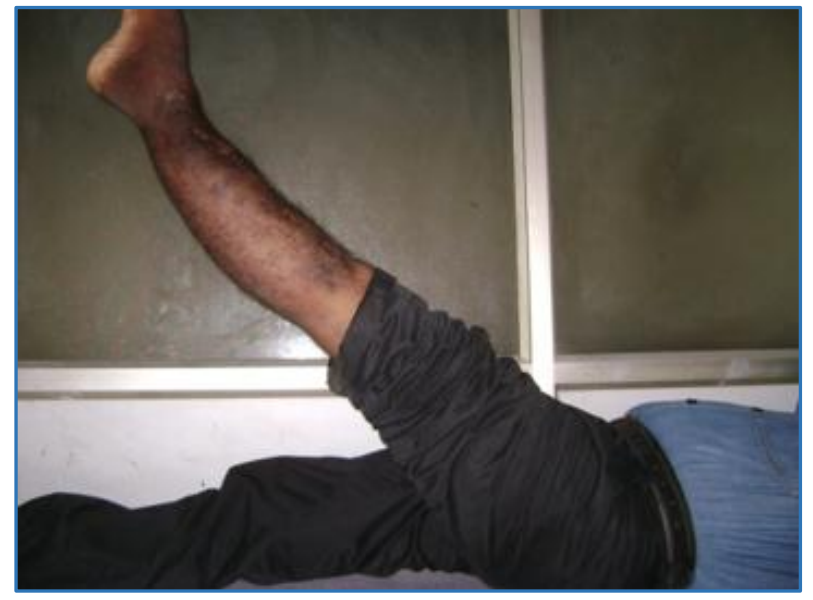

Figure 10. After Fixator Removal

\section{RESULTS}

In our study, all 40 cases were followed up until union. Patients were assessed for pain and functional limitations, examined for angular and rotational mal-alignment and range of motion. Limb lengths were measured clinically.

Pin tract infection occurred in $4(10 \%)$ cases. 2 resolved by systemic antibiotics for 5 days, one by soft tissue release around the offending wire and in the other the wires had to be completely removed and reapplied. $2(5 \%)$ patients had an angulation of $5^{\circ}$ at the fracture site, and $4(10 \%)$ had shortening between 1-2 $\mathrm{cm}$. Knee and ankle range of motion was satisfactory in almost all cases. There were no cases of osteomyelitis or neurovascular complications.

When there was evidence of callus formation in the followup x-rays, union was clinically verified by the absence of pain and motion while fully weight bearing on the tibia with the frame still attached and destabilised. If pain or angulations occurred, the frame was restabilised and immobilisation continued until the above criteria were met. A patella-tendon bearing cast was used for an additional 3 to 4 weeks. Union was determined to be the time when fracture healing occurred and all forms of immobilisation or support were discontinued. Union occurred at an average of 5.3 months (3.5 to 8.5 months). Based on Johner and Wruhs' criteria,(11) the final results were rated as excellent-30, good6 and fair-4. No poor results were seen.

In our study, fracture union rate was $100 \%$. Two cases went for delayed union which united after grafting. In our series, antibiotic cover was given only for 7 to 10 days. All the 40 cases were allowed to weight bear as pain permitted.

Acceptance: 4 patients of our study initially hesitated for bulky appearance of the frame.

\begin{tabular}{|c|c|c|}
\hline Mal Union & 2 & $5 \%$ \\
\hline Delayed Union & 2 & $5 \%$ \\
\hline Shortening & 4 & $10 \%$ \\
\hline Pin Tract Infection & 4 & $10 \%$ \\
\hline Table 8. Complications \\
\hline
\end{tabular}

\begin{tabular}{|c|c|c|}
\hline $\begin{array}{c}\text { Sl. } \\
\text { No. }\end{array}$ & $\begin{array}{c}\text { Grade of Pin } \\
\text { Tract Infection }\end{array}$ & $\begin{array}{c}\text { No. of } \\
\text { Patients }\end{array}$ \\
\hline 1 & Grade I & 2 \\
\hline 2 & Grade II & 2 \\
\hline 3 & Grade III & Nil \\
\hline \multicolumn{2}{|c|}{ Table 9. Grade of Pin Tract Infection } \\
\hline
\end{tabular}

Our protocol encouraged patient to partially weight bear within 48 hours progressing to full weight bearing within the limits of pain (Usually within the first week). General condition of the patient and the presence of other associated injuries also influenced the decision to weight bear. All the fractures in this series united. Shtarker(18) reported 32 open tibial fractures treated with Ilizarov fixator. Healing time was 21.9 weeks in patients with a single injury and 25.7 weeks with multiple trauma similar to the results reported by Schwartsman et al.(19)

Even though the circumstances were adverse with respect to the fracture pattern, the union time was not unduly prolonged. However, cases that required corticotomy and distraction necessitated prolongation of the time on the fixator. This is an additional option with the Ilizarov fixator that makes it so versatile.

\section{CONCLUSION}

From our study of 40 cases of management of grossly comminuted compound fracture of tibia with Ilizarov technique, we conclude that Ilizarov technique has a definite role in the management of fracture of tibia like open comminuted fracture, open segmental fracture and open fracture with bone loss.

It reduces hospital stay, allows full functional recovery, permits early weight bearing and gives definite union.

Pain during treatment and acceptance of apparatus were two important subjective problems encountered in our experiences.

Early weight bearing even in severely comminuted fractures is the key factor that separates Ilizarov from other methods of fixation. It promotes early functional recovery, eliminating fracture disease. Dynamisation and correction of deformities in any plane is easily accomplished. Frame constructs could be modified to facilitate wound cover and access. Thus, it lends the much-needed flexibility in complex fractures.

\section{REFERENCES}

[1] Monti K, Michael JB, David BH, et al. Outcome in open tibia fractures: relationship between delay in treatment and infection. Journal Trauma 2003;55(5):949-54.

[2] Heckman JD, Sarasohn-Kahn J. The economics of treating tibia fracture. The cost of delayed unions. Bull Hosp Jt Dis 1997;56(1):63-72.

[3] Grütter R, Cordey J, Bühler M, et al. The epidemiology of diaphyseal fractures of the tibia. Injury 2000;31(Suppl 3):C64-7.

[4] Park K. Accidents. In Park's textbook of preventive and social medicine. 16th edn. M/s Banarsidas Bhanot, 1167, Premnagar, Jabalpur, India. 2000:301-4.

[5] Mishra AK. A polypropylene protection device in preventions of tibial shaft fractures in two-wheeled vehicle drivers. J Orthopaedics 2006;3(1)e7.

[6] McQueen MM, Gaston P, Court-Brown CM. Acute compartment syndrome. Who is at risk? J Bone Joint Surg Br 2000;82(2):200-3.

[7] Witschi TH, Omer GE. The treatment of open tibial shaft fractures from Vietnam War. J Trauma 1970;10(2):105-11. 
[8] Clancey GJ, Hansen ST. Open fractures of the tibia: a review of one hundred and two cases. J Bone Joint Surg Am 1978;60(1):118-22.

[9] Gustilo RB, Anderson JT. Prevention of infection in the treatment of one thousand and twenty-five open fractures of long bones. J Bone Joint Surg Am 1976;58:453-61.

[10] Mayr E. Tibial fractures. Chirurg 2002;73:642-61; quiz 662-3.

[11] Johner R, Wruhs O. Classification of tibial shaft fractures and correlation with results after rigid internal fixation. Clin Orthop Relat Res 1983;178:7-25.

[12] Bilat C, Leutenegger A, Ruedi T. Osteosynthesis of 245 tibial fractures: early and late complications. Injury 1994;25(6):349-58.

[13] Williams J, Gibbons M, Trundle H, et al. Complications of nailing in closed tibial fractures. J Orthop Trauma 1995;9(6):476-81.

[14] Hupel TM, Weinberg JA, Aksenov SA, et al. Effect of unreamed, limited reamed and standard reamed intramedullary nailing on cortical bone porosity and new bone formation. J Orthop Trauma 2001;15(1):1827.
[15] Kessler SB, Hallfeldt KK, Perren SM, et al. The effects of reaming and intramedullary nailing on fracture healing. Clin Orthop Relat Res 1986;212:18-25.

[16] Cierny G, Byrd HS, Jones RE. Primary versus delayed soft-tissue coverage for severe open tibial fractures. A comparison of results. Clin Orthop Relat Res 1983;178:54-63.

[17] Tukiainen E, Asko-Seljavaara S. Use of the Ilizarov technique after a free microvascular muscle flap transplantation in massive trauma of the lower leg. Clin Orthop Relat Res 1993;297:129-34.

[18] Shtarker H, David R, Stolero J, et al. Treatment of open tibial fractures with primary suture and Ilizarov fixation. Clin Orthop Relat Res 1997;335:268-74.

[19] Schwartsman V, Martin SN, Ronquist RA, et al. Tibial fractures. The Ilizarov alternative. Clin Orthop Relat Res 1992;278:207-16. 